\title{
Sources of Knowledge about CPR and Its Association with Demographical Characteristics in Saudi Arabia
}

\author{
Osama Saud H. Aljameel ${ }^{1}$, Amer Abdulaziz D. Alhuwayfi ${ }^{1}$, Khadijah Salem M. Banjar ${ }^{1}$, \\ Salem Hmoud Salem Alswayda', Rahaf Abdulmonem Alhijaili', Ali E. M. Elkandow ${ }^{2}$, \\ Hussain Gadelkarim Ahmed1 \\ ${ }^{1}$ College of Medicine, University of Hail, Hail, Saudi Arabia \\ ${ }^{2}$ Department of Emergency, King Khalid Hospital, Hail, Saudi Arabia \\ Email: hussaingad5@gmail.com
}

How to cite this paper: Aljameel, O.S.H., Alhuwayfi, A.A.D., Banjar, K.S.M., Alswayda, S.H.S., Alhijaili, R.A., Elkandow, A.E.M. and Ahmed, H.G. (2018) Sources of Knowledge about CPR and Its Association with Demographical Characteristics in Saudi Arabia. Open Journal of Emergency Medicine, 6, 43-53.

https://doi.org/10.4236/ojem.2018.63007

Received: August 30, 2018

Accepted: September 22, 2018

Published: September 25, 2018

Copyright (๑) 2018 by authors and Scientific Research Publishing Inc. This work is licensed under the Creative Commons Attribution International License (CC BY 4.0).

http://creativecommons.org/licenses/by/4.0/

(c) (i) Open Access

\begin{abstract}
Background: Bystander cardiopulmonary resuscitation (CPR) is a vital element of patient survival. Therefore, the aim of the present study was to assess sources of knowledge about CPR and its association with demographical characteristics in Saudi Arabia. Methodology: Data about CPR were obtained from 440 Saudi volunteers living in the city of Hail, Northern Saudi Arabia. Results: Out of the 440 study subjects, 257/440 (58.4\%) individuals were found to know about CPR. Out of 257 individuals, 154/257 (60\%) were males and 103/257 (40\%) were females. Conclusion: The level of awareness toward CPR in general population of Northern Saudi Arabia, which requires more efforts at community basis. The most effective source for raising awareness is the appropriate utility of social media, as well as, implementing sustainable program for delivering CPR training courses evolving all community settings.
\end{abstract}

\section{Keywords}

CPR, Social Media, CPR Training, Television, Saudi Arabia, Hail

\section{Introduction}

In cardiac arrest, high quality cardiopulmonary resuscitation (CPR) is a key determinant of patient survival [1]. CPR is a collection of interventions performed to provide oxygenation and circulation to the body during cardiac arrest [2]. Seventy percent of cardiac arrests that occur outside of a hospital happen in the home. Other people never witness half of these cardiac arrests. Despite advances 
in emergency medical services, the survival rate remains low. Adult victims of non-traumatic cardiac arrest that receive resuscitation attempts by emergency medical services have a rate of survival to hospital discharge of only $10.8 \%$. In comparison, adult patients who develop cardiac arrest in a hospital setting have rates of survival to hospital discharge of up to $25.5 \%$ [3].

In the event of cardiac arrest, basic life support can be effective to reduce the chance of death. According to the 2015 American Heart Association Guidelines [4] [5], the quality of CPR is an important and often overlooked factor affecting survival. Individual factors, training, awareness, technique and rescuer fatigue may influence the quality of CPR. Strategies to improve the quality of CPR include research, training, education as well as incorporating appropriate technologies that measure and feedback the quality of CPR [6].

Despite the strong evidence that basic life support including cardiopulmonary resuscitation (CPR) improves survival rates after cardiac events, the awareness and training among citizens of Saudi Arabia is low [7]. Public awareness and knowledge on CPR was inadequate even among the younger population, and among parents with disabled children. The general public was willing to improve their knowledge and skills of CPR [8]. Therefore, the aim of the present study was to assess sources of knowledge about CPR and its association with demographical characteristics in Saudi Arabia.

\section{Materials and Methods}

In this community based cross-sectional survey, data about CPR were obtained from 440 Saudi volunteers living in the city of Hail, Northern Saudi Arabia during the period from October 2017 to June 2018. Participants were randomly selected by simple random regardless to age, gender and education or occupation.

A Purposeful questionnaire was designed and used for obtaining of the necessary data. The following information were obtained from each participant: age, sex, and education level, previous information about CPR, and source of information about CPR.

\subsection{Ethical Consent}

Each participant was asked to sign a written ethical consent during the questionnaire's interview. The informed ethical consent form was designed and approved by the ethical committee of the College of Medicine (University of Hail, Saudi Arabia) Research Board.

\subsection{Data Analysis}

Statistical Package for Social Sciences (version 16) was used for analysis and to perform Pearson Chi-square test for statistical significance (P value). The 95\% confidence level and confidence intervals were used. $P$ value less than 0.05 was considered statistically significant. 


\section{Results}

This is a cross sectional survey investigated 440 volunteers for their knowledge about CPR, as well as, the source of this knowledge. Out of 440 contributors, $248 / 440(56.3 \%)$ were males and 192/440 (43.7\%) were females, their ages ranging from 18 to 70 years old.

Out of the 440 study subjects, $257 / 440$ (58.4\%) individuals were found to know about CPR. Out of 257 individuals, 154/257 (60\%) were males and 103/257 (40\%) were females. Although the results seemed to be similar, but males were has more knowledge about CPR than females. The 95\% confidence interval (95\% $\mathrm{CI})$ and odd ratio $(\mathrm{OR})$; OR $(95 \% \mathrm{CI})=1.4156(0.9657$ to 2.0751$), \mathrm{P}$ value $=$ 0.0749 .

As indicated in Table 1, the majority of participants were at age group 18 - 25 years followed by age groups, 40+ and 31 - 35 years, constituting 105/257 (40.6\%), 66/257 (25.7\%) and 37/257 (14.4\%), respectively. For males, most of them were found at age group 18 - 25 years followed by $40+$ years constituting $56 / 154(36.4 \%)$ and $47 / 154(30.5 \%)$, respectively. For females, most of them were found at age group 18 - 25 years followed by $40+$ years constituting 49/103 (47.6\%) and 19/103 (18.4\%), respectively, as shown in Figure 1.

Table 1. Distribution of the study population by demographical characteristics.

\begin{tabular}{|c|c|c|c|c|}
\hline Variable & Category & Males & Females & Total \\
\hline \multicolumn{5}{|l|}{ Age } \\
\hline & $18-25 \mathrm{yrs}$ & 56 & 49 & 105 \\
\hline & $26-30 \mathrm{yrs}$ & 21 & 15 & 36 \\
\hline & $31-35 \mathrm{yrs}$ & 22 & 15 & 37 \\
\hline & $36-40$ yrs & 8 & 5 & 13 \\
\hline & $40+y r s$ & 47 & 19 & 66 \\
\hline & Total & 154 & 103 & 257 \\
\hline \multicolumn{5}{|l|}{ Education } \\
\hline & Basic & 52 & 41 & 93 \\
\hline & University & 89 & 58 & 147 \\
\hline & Post-university & 13 & 4 & 17 \\
\hline & Total & 154 & 103 & 257 \\
\hline \multicolumn{5}{|l|}{ Occupation } \\
\hline & Educators & 26 & 31 & 57 \\
\hline & Students & 58 & 49 & 107 \\
\hline & Employees & 44 & 5 & 49 \\
\hline & Self-employed & 24 & 3 & 27 \\
\hline & Jobless & 2 & 15 & 17 \\
\hline & Total & 154 & 103 & 257 \\
\hline
\end{tabular}




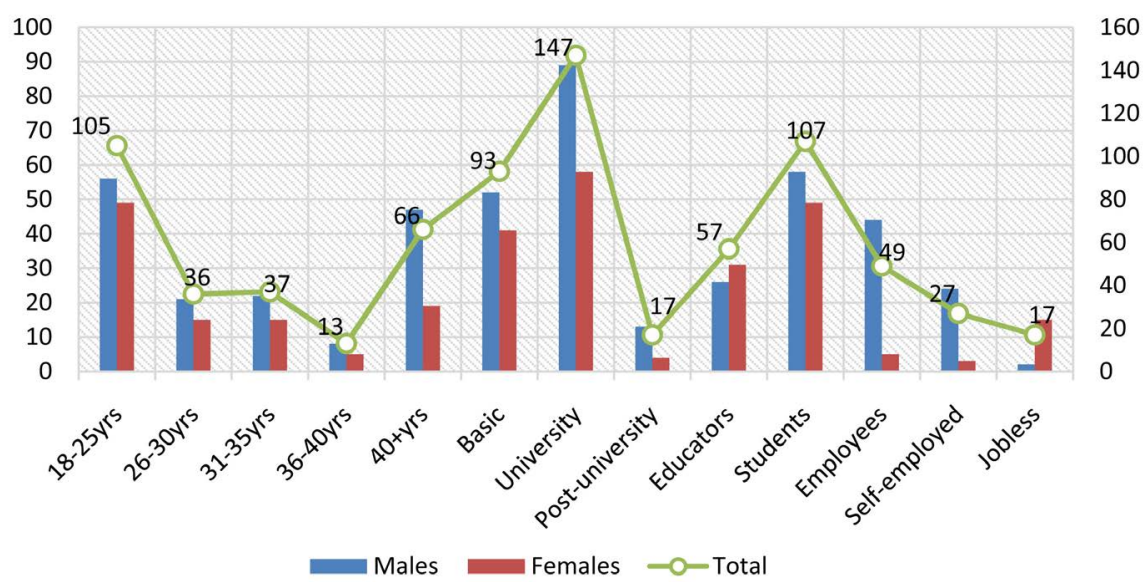

Figure 1. Description of the study population by demographical characteristics.

With regard to the education levels, the great majority of the participants were with a university level followed by those with basic education levels representing $147 / 257$ (57\%) and 93/257 (36\%) in this order. For males, most of them were found with university level followed by basic levels, representing 89/154 (57.8\%) and 52/154 (33.8\%) correspondingly. Also the case for females is similar, most participants were found with university level followed by basic constituting 58/103 (56\%) and 41/103 (39.8\%) correspondingly, as indicated in Table 1, Figure 1.

With regard to the occupation, the majority of participants were students followed by educators and employees constituting 107/257 (41.6\%), 57/257 (22.2\%) and 49/257 (19\%), respectively. For males, most of them were students followed by employees constituting 58/154 (37.7\%) and 44/154 (28.6\%) in this order. For males most of them were students followed by educators representing 49/103 (47.6\%) and 31/103 (30\%), respectively, as indicated in Table 1, Figure 1.

As indicated in Table 2, the most common source of information about CPR was social media followed by CPR training courses, education centers and reading in the media, representing $91 / 257$ (35.4\%), 51/257 (19.8\%), 40/257 (15.6\%) and 26/257 (10\%), respectively as shown in Figure 2. For males, the majority got their information about CPR from social media, followed by CPR training courses and education centers, representing 50/154 (32.5\%), 32/154 (20.8\%) and $30 / 154(19.5 \%)$ in this order.

For females, the majority got their information about CPR from social media, followed by CPR training courses and reading in the media, representing 41/103 (39.8\%), 19/103 (18.4\%) and 16/103/154 (15.5\%) in this order, as indicated in Table 2, Figure 2.

Table 3, Figure 3 Summarized the distribution of the study subjects by age and information about CPR. The majority of participants were found at age group 18 - 25 years followed by age groups $40+$ and 31 - 35 years representing 105, 66 and 37 participants, respectively. Most of those got their information about CPR from TV, were found at age range $18-25$ and 40+ years constituting 


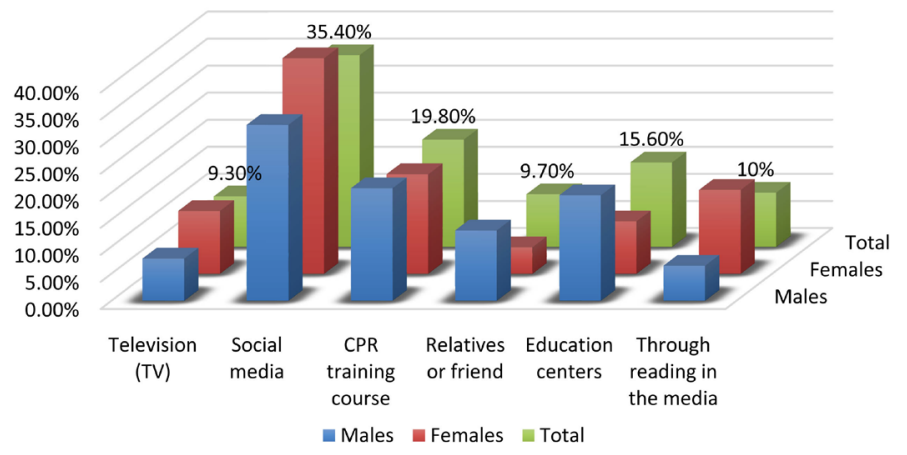

Figure 2. Description of the study population by sex and source of information about CPR.

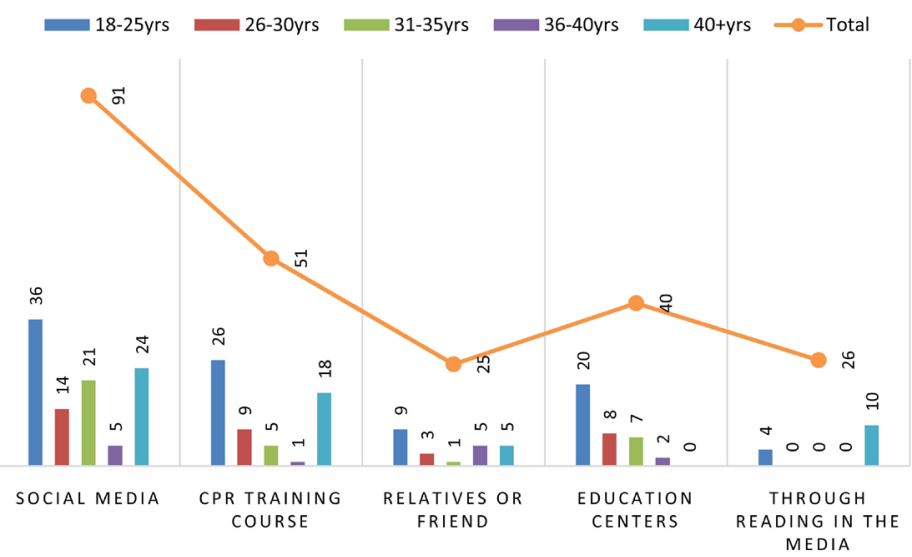

Figure 3. Description of the study population by age and source of information about CPR.

Table 2. Distribution of the study population by sex and source of information about CPR.

\begin{tabular}{cccc}
\hline Variable & Males & Females & Total \\
\hline Television (TV) & 12 & 12 & 24 \\
Social media & 50 & 41 & 91 \\
CPR training course & 32 & 19 & 51 \\
Relatives or friend & 20 & 5 & 25 \\
Education centers & 30 & 10 & 40 \\
Through reading in the media & 10 & 16 & 26 \\
Total & 154 & 103 & 257 \\
\hline
\end{tabular}

Table 3. Distribution of the study population by age and source of information about CPR.

\begin{tabular}{ccccccc}
\hline Variable & $\mathbf{1 8 - 2 5}$ & $\mathbf{2 6 - 3 0}$ & $\mathbf{3 1 - 3 5}$ & $\mathbf{3 6 - 4 0}$ & $\mathbf{4 0 +}$ & Total \\
\hline Television (TV) & 10 & 2 & 3 & 0 & 9 & 24 \\
Social media & 36 & 14 & 21 & 5 & 24 & 91 \\
CPR training course & 26 & 9 & 5 & 1 & 18 & 51 \\
Relatives or friend & 9 & 3 & 1 & 5 & 5 & 25 \\
Education centers & 20 & 8 & 7 & 2 & 0 & 40 \\
Through reading in the media & 4 & 0 & 0 & 0 & 10 & 26 \\
Total & 105 & 36 & 37 & 13 & 66 & 257 \\
\hline
\end{tabular}


10/24 (41.7\%) and 9/24 (37.5\%), respectively. For social media, most participants were found at age range 18-25 years followed by $40+$ and 31 - 35 representing 36/91 (39.5\%), 24/91 (26.4\%) and 21/91 (23\%), respectively. For CPR training course, most participants were found at age group 18 - 25 followed by $40+$ years and 26 - 30 years, representing 26/51 (50.9\%), 18/51 (35.3\%) and 9/51 (17.6\%), in this order. For, relatives or friend, most participants were found at age group 18 - 25 followed by 36 - 40 and 40+ years constituting 9/25 (36\%), 5/25 (20\%) and $5 / 25(20 \%)$ in this order. For reading in the media, most participants were found at age group 40+ followed by 18 - 25 years constituting 10/26 (38.5\%) and $4 / 26$ (15.4\%), respectively.

With regard to the relationship between education levels and the source of information about CPR, for people with basic education level, most of them got their knowledge from social media followed by reading in the media (such as newspapers, etc), education centers, constituting 25/93 (27\%), 19/93 (20.4\%), and $15 / 93(16 \%)$, respectively. For individuals with university level, most of them got their knowledge from social media followed by CPR training courses, and education centers, representing 59/147 (40\%), 34/147 (23\%), and 25/147 (17\%), correspondingly. For post-university, most of them got their knowledge from CPR training courses and social media, both constituting 7/17 (41.2\%), as indicated in Table 4, Figure 4.

The distribution of the study population by occupation and source of information about CPR was summarized in Table 5. For educators, most of them got their knowledge about CPR from social media followed by education centers, representing 25/57 (44\%) and 11/57 (19.3\%), respectively. For students, most of them got their knowledge from social media and CPR training courses, both representing 30/107 (28\%). For employees, most of the got their information from social media 20/49 (40.8\%). For self-employed, most of them got their knowledge from social media and TV representing 9/27 (33.3\%) and 7/27 (26\%) in this order. For jobless, most of them got their knowledge from social media and relatives or friends constituting $7 / 17$ (41\%) and 4/17 (23.5\%) correspondingly, as shown in Figure 5.

Table 4. Distribution of the study population by level of education and source of information about CPR.

\begin{tabular}{ccccc}
\hline Variable & Basic & University & Post-university & Total \\
\hline Television (TV) & 13 & 9 & 2 & 24 \\
Social media & 25 & 59 & 7 & 91 \\
CPR training course & 10 & 34 & 7 & 51 \\
Relatives or friend & 11 & 13 & 1 & 25 \\
Education centers & 15 & 25 & 0 & 40 \\
Through reading in the media & 19 & 7 & 0 & 26 \\
Total & 93 & 147 & 17 & 257 \\
\hline
\end{tabular}




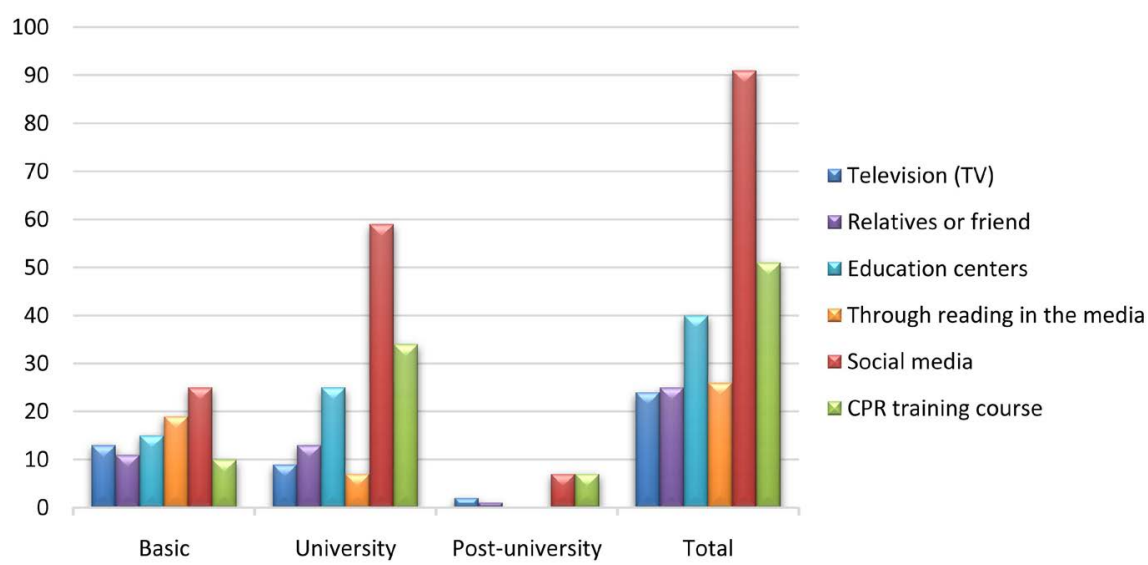

Figure 4. Description of the study subjects by level of education and source of information about CPR.

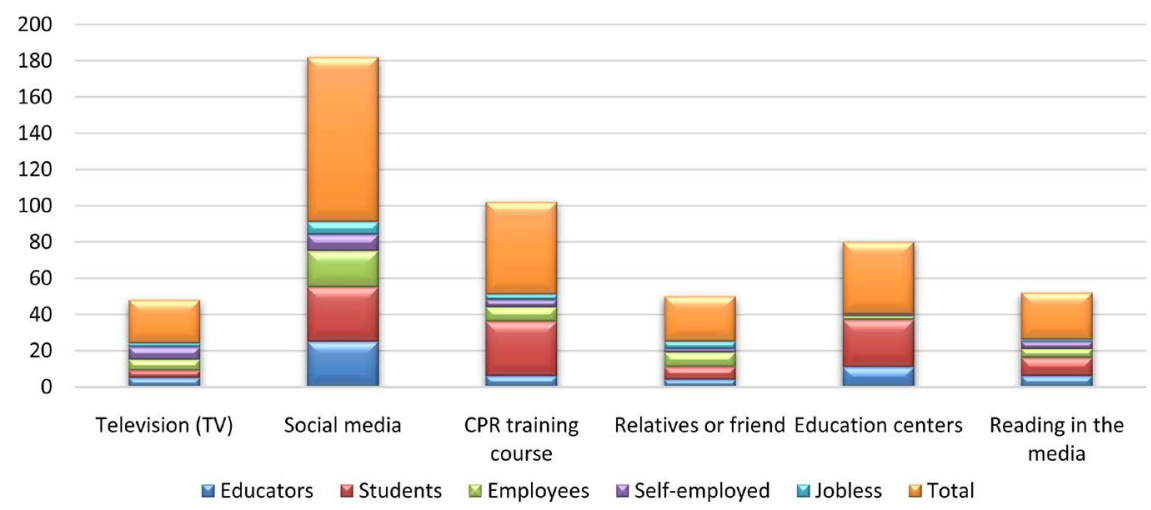

Figure 5. Description of participants by occupation and source of information about CPR.

Table 5. Distribution of the study population by occupation and source of information about CPR.

\begin{tabular}{ccccccc}
\hline Variable & Educators & Students & Employees & Self-employed & Jobless & Total \\
\hline Television (TV) & 5 & 4 & 6 & 7 & 2 & 24 \\
Social media & 25 & 30 & 20 & 9 & 7 & 91 \\
CPR training course & 6 & 30 & 8 & 4 & 3 & 51 \\
Relatives or friend & 4 & 7 & 8 & 2 & 4 & 25 \\
Education centers & 11 & 26 & 2 & 1 & 0 & 40 \\
Reading in the media & 6 & 10 & 5 & 4 & 1 & 26 \\
Total & 57 & 107 & 49 & 27 & 17 & 257 \\
\hline
\end{tabular}

\section{Discussion}

$\mathrm{CPR}$ is a growing lifesaving procedure, which involves a sequences of lifesaving actions that increase the survival rates next to sudden cardiac arrest (SCA) [9]. As SCA can occur outside the hospital and as CPR is an urgent action to be performed to save the life of the patient, it should be done by the bystanders who 
witnessed the event. Therefore, training of large sections people in communities with high cardiovascular diseases is an important public issue. To evolve large section of community in successful CPR training programs, there should be a preceding awareness programs. Moreover, to get more success in such programs, it is essential to understand the demographical complexity of the defined population. Therefore, the objective of the present study was to assess sources of knowledge about CPR and its association with demographical characteristics in Saudi Arabia.

In the present study about $43.6 \%$ of the study subjects didn't heard about CPR before. This represent a large portion of population with variable education levels and different occupation settings. However, there were few studies conducted in this context from Saudi Arabia with diverse findings. In a cross-sectional community-based survey included individuals visiting the first Pediatric Health Awareness Week held at Dammam University Hospital, of the participants, $80.8 \%$ of the females and $86.5 \%$ of males were totally unaware of CPR. Overall, $15.5 \%$ of all female participants had attended some CPR course(s) compared with $6.1 \%$ of the males; $18.7 \%$ of the females had watched CPR program (s)/video (s) on TV or online compared to $11.1 \%$ of the males [8]. Another study from Saudi Arabia to determine the current level of knowledge and CPR-skills among secondary school teachers, and to assess their attitudes and willingness to participate in regular CPR training. Among the teachers, 35.7\% had completed CPR training previously; but overall, CPR knowledge and skills were low (mean $=4.0, \mathrm{sd}=1.62$ ). In fact, the average scores did not differ between those who had training and those who did not. The majority of teachers wanted more training (64.9\%) and were willing to take a free course (78.4\%) [7].

In the present study males were more likely to know about CPR (60\%) compared to females (40\%). It was found that the factors most related with intention of bystander CPR were male gender, younger age, CPR awareness, recent CPR training, and qualified CPR learning [10].

In the present study the most common source of information about CPR was social media followed by CPR training courses, education centers and reading in the media, representing $35.4 \%, 19.8 \%, 15.6 \%$ and $10 \%$, respectively. Effective communication is a critical function within any public health system. Social media has enhanced communication between individuals and organizations and has the potential to augment public health communication [11]. However, there is a lack of reported data on social media adoption within public health settings. As recognized by Bosley et al. [12] tweets related to cardiac arrest fit into three types: personal information sharing, general information sharing and information seeking. The tweets were further categorized as containing information related to specific cardiac events, CPR performance, resuscitation-related education, research or news and specific questions about cardiac arrest. Despite a large volume of tweets, Twitter can be filtered to identify public knowledge and information seeking and sharing about cardiac arrest. To better engage via social media, healthcare providers can distil tweets by user, content, temporal trends, 
and message dissemination. Further understanding of information shared by the public in this forum could suggest new approaches for improving resuscitation related education [13].

With reference to age, in the present study there was increased number of participants at younger and older age groups. Other wide there is no differences in age groups as well as in the sex regarding knowledge about CPR. Within age groups, 18 - 25, 26 - 30 years, most participants got their knowledge from Social media followed by CPR training courses. For age group 31 - 35 years, most participants got their knowledge about CPR from social media and education centers including schools and universities. However, the major sources for older people were also social media and CPR training courses. Thus social media can be considered as a major source for raising the public awareness towards different community related health issues, regardless of age in Northern Saudi Arabia.

With regard to education, the majority of participants in the present study were with university level of education followed by general education. For basic education (general), most participants got their information about CPR through social media followed by reading in the media (such as newspapers). On the other hand, for those with university level of education most of them got their knowledge from social media followed by CPR training courses, and this is cases for those at post-university levels of education. However, in recent years, there was development in education methods, which allows the introduction of out curriculum inclusion of certain new-fangled medical issues. Such events rendered educated people more oriented towards CPR [14].

With regard to occupation and source of information about CPR, for educators (teacher, lectures etc), most of them got their information from social media and education centers. Students got their knowledge predominantly from both social media and CPR training courses. School CPR training has become mandatory in many countries, but whether legislation has translated into implementation of CPR training is largely unknown. Completed CPR training was associated with believing other schools were conducting training, awareness of mandating legislation, presence of a school CPR training coordinator, teachers teacher feeling competent to conduct training, and having easy access to training material. Facilitating these factors may increase rates of school CPR training [15].

With regard to the employees, self-employed and jobless, the great majority of participants got their information about CPR from social media. Work site health promotion is a comprehensive approach to improving health and includes awareness, health education, behavioral change, and organizational health initiatives. Wellness programs usually include stress management, smoking cessation, weight management, $\mathrm{CPR}$ and first aid classes, and employee assistance programs (EAPs) [15]. In addition of the contribution of the present study in presenting the current status of CPR in Saudi community it will further stimulate health providers as well as researchers to effectively contribute to promote CPR practice in Saudi Arabia. 


\section{Conclusion}

The level of awareness toward CPR in general population of Northern Saudi Arabia requires more efforts at community basis. The most effective source for raising awareness is the appropriate utility of social media, as well as, implementing sustainable program for delivering CPR training courses evolving all community settings.

\section{Acknowledgements}

Authors would like to thank all participants for their help in collecting the data for this study. Also authors would like to thank Dr. Ali Dawood Mohammed Almansour and Dr. Abdullah Abdlhadi Hammad Alharbi, for their considerable help in data collection.

\section{Conflicts of Interest}

The authors declare no conflicts of interest regarding the publication of this paper.

\section{References}

[1] Cardiopulmonary Resuscitation Specialized Committee of Chinese Research Hospital Association; the Science Popularization Branch of the Chinese Medical Association, Wang, L., Meng, Q. and Yu, T. (2018) National Consensus on Cardiopulmonary Resuscitation Training in China. Zhonghua Wei Zhong Bing Ji Jiu Yi Xue, 30, 385-400.

[2] Sciammarella, J.C. and Patel, P.H. Cardiopulmonary Resuscitation. StatPearls StatPearls Publishing, Treasure Island. https://www.ncbi.nlm.nih.gov/books/NBK470402/

[3] Kleinman, M.E., Brennan, E.E., Goldberger, Z.D., Swor, R.A., Terry, M., Bobrow, B.J., et al. (2015) Part 5: Adult Basic Life Support and Cardiopulmonary Resuscitation Quality: 2015 American Heart Association Guidelines Update for Cardiopulmonary Resuscitation and Emergency Cardiovascular Care. Circulation, 132, S414-S435. https://doi.org/10.1161/CIR.0000000000000259

[4] Travers, A.H., Perkins, G.D., Berg, R.A., Castren, M., Considine, J., Escalante, R., et al. (2015) Part 3: Adult Basic Life Support and Automated External Defibrillation: 2015 International Consensus on Cardiopulmonary Resuscitation and Emergency Cardiovascular Care Science with Treatment Recommendations. Circulation, 132, S51-S83. https://doi.org/10.1161/CIR.0000000000000272

[5] Ong, E.H. (2011) Improving the Quality of CPR in the Community. Singapore Medical Journal, 52, 586-591.

[6] Al Enizi, B.A., Saquib, N., Zaghloul, M.S.A., Alaboud, M.S.A., Shahid, M.S. and Saquib, J. (2016) Knowledge and Attitudes about Basic Life Support among Secondary School Teachers in Al-Qassim, Saudi Arabia. International Journal of Health Sciences, 10, 415-422.

[7] Al-Turkistani, H.K. (2014) Awareness and Knowledge of Pediatric Cardio-Pulmonary Resuscitation in the Community of Al-Khobar City. Journal of Family \& Community Medicine, 21, 125-129. https://doi.org/10.4103/2230-8229.134772

[8] Sasson, C., Rogers, M.A., Dahl, J. and Kellermann, A.L. (2010) Predictors of Surviv- 
al from Out-of-Hospital Cardiac Arrest: A Systematic Review and Meta-Analysis. Circulation: Cardiovascular Quality and Outcomes, 3, 63-81. https://doi.org/10.1161/CIRCOUTCOMES.109.889576

[9] Lee, M.J., Hwang, S.O., Cha, K.C., Cho, G.C., Yang, H.J. and Rho, T.H. (2013) Influence of Nationwide Policy on Citizens' Awareness and Willingness to Perform Bystander Cardiopulmonary Resuscitation. Resuscitation, 84, 889-894. https://doi.org/10.1016/j.resuscitation.2013.01.009

[10] Thackeray, R., Neiger, B.L., Smith, A.K. and Van Wagenen, S.B. (2012) Adoption and Use of Social Media among Public Health Departments. BMC Public Health, $12,242$.

[11] Bosley, J.C., Zhao, N.W., Hill, S., Shofer, F.S., Asch, D.A., Becker, L.B., et al. (2012) Decoding Twitter: Surveillance and Trends for Cardiac Arrest and Resuscitation Communication. Resuscitation, 83, 206-212.

[12] Bosley, J.C., Zhao, N.W., Hill, S., et al. (2013) Decoding Twitter: Surveillance and Trends for Cardiac Arrest and Resuscitation Communication. Resuscitation, 84, 206-212. https://doi.org/10.1016/j.resuscitation.2012.10.017

[13] Narayan, D.P.R., Biradar, S.V. and Reddy, M.T. (2015) Assessment of Knowledge and Attitude about Basic Life Support among Dental Interns and Postgraduate Students in Bangalore City, India. World Journal of Emergency Medicine, 6, 118-122. https://doi.org/10.5847/wjem.j.1920-8642.2015.02.006

[14] Malta Hansen, C., Zinckernagel, L., Ersbøll, A.K., et al. (2017) Cardiopulmonary Resuscitation Training in Schools Following 8 Years of Mandating Legislation in Denmark: A Nationwide Survey. Journal of the American Heart Association: Cardiovascular and Cerebrovascular Disease, 6, e004128. https://doi.org/10.1161/JAHA.116.004128

[15] Fronstin, P. (1996) Health Promotion and Disease Prevention: A Look at Demand Management Programs. EBRI Issue Brief, 177, 1-14. 